\title{
Gold-Catalysed Oxidation of Carbon Monoxide
}

\author{
Geoffrey C Bond \\ Brunel University, Uxbridge, Middlesex, UB8 3PH, UK \\ and David T Thompson \\ Newlands' The Village, Whitchurch Hill, Reading, RG8 7PN, UK
}

\begin{abstract}
Of the many important reactions that are known to be catalysed by gold particles supported on transition metal oxides, the oxidation of carbon monoxide is of outstanding significance: the current state of understanding of its mechanism is reviewed, and discordant observations reported in the literature are noted and analysed. A general mechanism involving reaction at the edge of a particle containing both gold atoms and ions, and involving the support, is suggested, although not all features of it are necessarily always operative. Possible practical uses for gold in catalysing this reaction include pollution control, fuel cells, and gas sensing.
\end{abstract}

The last decade has witnessed a rapid growth of interest in the catalytic properties of gold: when it is suitably employed, and much skill is needed to achieve this, supported gold is capable of catalysing a wide variety of reactions under comparatively mild conditions, including oxidation, oxidative dehydrogenation, hydrogenation, and many others. We have recently reviewed this sector of catalysis in depth (1), and other review articles have been published (2, 3); the earlier Gold Bulletin review also provides a general survey (4). One of the main conclusions from our previous review (1) was that the way in which gold acts catalytically is substantially different from that adopted by metals of the Platinum Group.

Probably the greatest surprise has been the ability of appropriately prepared gold catalysts to effect the oxidation of carbon monoxide at very moderate temperatures: the best have even been reported to function below ambient temperature, and to be more active than conventionally prepared palladium and platinum catalysts. Because of the potential for practical application, as well as intrinsic scientific interest, the flow of publications continues unabated. We have recorded some 60 publications in 1999, and at least half of these concern carbon monoxide oxidation. However, a reader of the recent literature, as well as of the earlier publications already reviewed (1), cannot fail to experience a sense of confusion at the many methods of preparation and characterization that have been used, the many different supports, and in particular at the various and often contradictory reports on the importance of the experimental variables. It is little wonder, therefore, that almost all discussions of reaction mechanisms are of an elementary and somewhat speculative nature, because of the lack of a firm foundation of reaction kinetics and spectroscopic data analysis.

The main reason for this review is to try to understand the reasons for the many discrepancies and contradictions which the literature reveals. These reflect the very critical and multiple criteria which must be met before high catalytic activity can be obtained, and the extreme sensitivity of the final catalyst to all stages of its preparation and treatment before use. Although all is as yet far from clear, there are enough indicators towards a possible model that will accommodate many of the observations, and a mechanistic concept is tentatively advanced later in this paper.

\section{CONSENSUAL OBSERVATIONS}

Notwithstanding the seemingly confused state of the literature, there is a large measure of agreement as to the principal factors responsible for the activity (or inactivity) of gold catalysts evaluated for carbon monoxide oxidation, and it will be helpful to start by listing these.

1 Unsupported gold in the form of sponge, wire, powder, etc, and large supported gold particles are at best only weakly active for carbon monoxide 
oxidation (5 - 7), although fine gold powder (mean particle size $76 \mathrm{~nm}$ ) shows activity between 249 and $294 \mathrm{~K}(8)$.

2 Much higher activities are shown by oxidesupported small gold particles less than about $5 \mathrm{~nm}$ in size, with the highest rates being shown at sizes of about 2 to $3 \mathrm{~nm}(1,9-11)$. This is true whatever the method of preparation employed; they may originate as a colloidal dispersion with uniform sized gold particles $(12-14)$ or be formed by vapour deposition $(2,15-18)$, or by controlled aggregation of atoms or ions in simple gold compounds $(1,19$ 22 , etc).

3 Choice of support is very important: success depends on using an oxide of the first row of the Transition Series elements in Groups $4-12$ (2), compounds which have not previously found much use as supports for the Platinum Group Metals. Of these, the oxides of titanium and iron have recently commanded the most interest, although those of manganese, cobalt and nickel are also effective (1). Many other oxides, including magnesia $(23-26)$, and the conventional alumina and silica $(3,27,28)$ have also been studied but are generally less efficient.

4 The method of preparation is critical. The traditional methods, such as ion exchange and impregnation $(10,20,29,30)$, are not very successful although successive reduction and calcination can generate activity in the impregnated material (10). Three methods in particular have been widely used: (i) coprecipitation, in which the support and gold precursors are brought out of solution, perhaps as hydroxides, by adding a base such as sodium carbonate; (ii) depositionprecipitation, in which the gold precursor is precipitated onto a suspension of the pre-formed support by raising the $\mathrm{pH}$, and (iii) Iwasawa's method in which a gold-phosphine complex (eg $\left.\left[\mathrm{Au}\left(\mathrm{PPh}_{3}\right)\right] \mathrm{NO}_{3}\right)$ is made to react with a freshly precipitated support precursor. These methods have been described in more detail in our earlier review (1), and the chemistry of Iwasawa's method has been described in detail (2). The use of urea as a hydrolysing agent has now been introduced (31). Other procedures such as the use of colloids (12 - 14), grafting (3) and vapour deposition (2, 15 -18) meet with varying degrees of success.

5 The mode of pretreatment before use is also important: calcination is frequently used with good results, while reductive procedures are usually not helpful.

\section{DISPUTED OBSERVATIONS}

All would agree that the foregoing paragraphs correspond to the general experience of workers in the field; it is, however, when one tries to elucidate the quantitative importance of these factors that disagreements start to emerge. For example:

1 How effectively does gold itself catalyse oxidation of carbon monoxide $(8,10)$ ?

2 Does the activity of a catalyst decrease with time on stream (20), or does it increase (21), before attaining a steady state?

3 In what circumstances is calcination either desirable or essential, and what are the best conditions to use? Some investigators report highest activities with uncalcined catalysts $(1,21,32)$.

4 Are the catalytically active gold species zero-valent atoms $\left(\mathrm{Au}^{\circ}\right)$ or oxidized species $\left(\mathrm{Au}^{\mathrm{I}}\right.$ or $\left.\mathrm{Au}^{\mathrm{III}}\right)$ ?

5 Kinetic parameters (orders of reaction, activation energy) seem to vary widely and irrationally; what are the factors that are responsible?

\section{UNSATISFACTORY ASPECTS OF THE EXPERIMENTAL WORK}

When a new field of research potentially as large as 'catalysis by gold' opens up, it is inevitable that each piece of research and each publication will only be able to tackle a very small part of the whole, so that opportunities for cross-checking will be minimal. Moreover 'catalysis by gold' exhibits many novel and unexpected features not shown by other catalytically active metals, and for which research workers have been unprepared: these features, and the tight constraints within which activity appears, largely explain the late development of the field and add to the problems faced when trying to review the topic. The unsatisfactory nature of the published work therefore stems from the necessarily limited and very specific nature of each contribution, and thus from the sheer scope of the field, and its numerous relevant variables. It is nevertheless worth listing a number of points which, were they to receive sufficient attention, would probably remove many of the ambiguities and uncertainties which surround past work:

1 Physical characterization of catalysts is often very sketchy; for example, BET surface area measurements (surely one of the simplest things to do) are often not reported, and estimates of mean gold particle size (eg by TEM) are often lacking. There are different opinions about the value of EXAFS for characterizing supported gold (eg 3, 22, 33). 
2 Some papers focus predominantly on the use of one method for characterization (eg XPS (22) or Mössbauer spectroscopy (eg 3, 21, 26, 32). The more the merrier!

3 More importantly, there is little appreciation of the chemical and physical changes that can occur during instrumental characterization, through the effects of UHV and of radiation (33). There is a particular risk that oxidized gold species may be reduced to $\mathrm{Au}^{0}$ during examination: a kind of Heisenberg's Uncertainty Principle applies (ie looking at the catalyst changes it). It might be quite dangerous to infer what species are catalytically active on the basis of what is revealed by XPS, XRD etc because the irradiation used may change the electronic structure of the catalyst being examined.
4 Post-reaction characterization is more useful than pre-reaction studies, but it is not often done. There have been few in situ studies during reaction, eg by FTIR (10).

5 Activity measurements are usually based on a single set of conditions (temperature, $\mathrm{O}_{2} / \mathrm{CO}$ ratio, flowrate or contact time): possibly important changes of rate with time on stream are not always reported, and when they are the statements are usually only qualitative. The times at which rates are measured are not always recorded, and observations on reaction kinetics are few and far between (see Table 1).

6 Comparisons are made between rates and other kinetic parameters based on the use of very different reactant concentrations (see Table 1), contact times and other variables: in particular there seems to be

Table 1 Kinetics of Carbon Monoxide Oxidation on Supported Gold Catalysts. Rate $\propto P_{C O}{ }^{x} P_{O_{2}}{ }^{y}$

\begin{tabular}{|c|c|c|c|c|c|c|c|c|c|}
\hline Support & Method* & {$[\mathrm{Au}](\%)$} & $d(n m)$ & $\begin{array}{c}\mathrm{T} \text { (range) } \\
(\mathrm{K})\end{array}$ & $\mathbf{x}$ & $y$ & $\begin{array}{c}E \\
\left(\mathbf{k J} \mathrm{mol}^{-1}\right)\end{array}$ & $\mathrm{O}_{2} / \mathrm{CO}$ & Ref \\
\hline$\alpha-\mathrm{Fe}_{2} \mathrm{O}_{3}$ & COP & 0.66 & 4 & $\begin{array}{c}304 \\
(273-333)\end{array}$ & 0 & 0.05 & 35.1 & 20 & 34 \\
\hline $\mathrm{FeO}_{x}$ & COP & 3.15 & 6.5 & $\begin{array}{c}353 \\
(313-373)\end{array}$ & 0.55 & 0.27 & 31 & - & 19 \\
\hline $\mathrm{FeO}_{x}$ & IWA & 3 & 2.9 & $\begin{array}{r}217 \\
(-)\end{array}$ & 0.03 & 0.35 & 28 & - & 37 \\
\hline $\mathrm{CO}_{3} \mathrm{O}_{4}$ & $\mathrm{DP}$ & 1.2 & $6-7$ & $\begin{array}{c}273 \\
(253-323)\end{array}$ & 0.05 & 0.27 & 16.3 & 20 & 34 \\
\hline $\mathrm{Ce}(\mathrm{Ca}) \mathrm{O}_{x}$ & COP & 5 & 8 & $\begin{array}{c}283-327 \\
(283-327)\end{array}$ & 0.30 & 0.18 & $53.7 * *$ & 8 & 35 \\
\hline $\mathrm{TiO}_{2}$ & DP & 3.3 & 2 & $\begin{array}{c}273 \\
(263-313)\end{array}$ & 0.05 & 0.24 & 34.3 & 20 & 34 \\
\hline $\mathrm{TiO}_{2}$ & IMP & 2.3 & $25-30$ & $\begin{array}{c}313 \\
(-)\end{array}$ & $\begin{array}{l}0.24 \\
-0.6\end{array}$ & 0.4 & $\begin{aligned} & \sim 38 \\
& \sim 10 * * *\end{aligned}$ & 1 & 6 \\
\hline $\mathrm{TiO}_{2}$ & COP & 1.0 & 33 & $\begin{array}{c}293 \\
(-)\end{array}$ & 0.43 & 0.03 & 30.5 & 1 & 10 \\
\hline $\mathrm{TiO}_{2}$ & COP & 1.0 & 33 & 313 & 0.56 & 0.13 & - & - & 10 \\
\hline $\mathrm{TiO}_{2}$ & IWA & 3 & - & $\begin{array}{c}263 \\
(-)\end{array}$ & 0.25 & 0.41 & 24 & - & 38 \\
\hline
\end{tabular}

\footnotetext{
Notes

I The first temperature is that at which orders of reaction were measured: the range in brackets is that used for activation energy.

2 A dash means that information was not provided.

3 The quoted $\mathrm{O}_{2} / \mathrm{CO}$ ratio is that used for the activation energy.

* $\quad \mathrm{COP}=$ coprecipitation; $\mathrm{DP}=$ deposition precipitation; $I \mathrm{MP}=$ impregnation; $I \mathrm{WA}=$ I wasawa's method in which gold-phosphine complexes react with freshly precipitated support precursor.

** This activation energy is true : the others are apparent

**** The lower value was found above $360 \mathrm{~K}$
} 
little appreciation of how for example apparent activation energy may depend on reactant pressures, or how orders of reaction may depend on temperature.

7 Statements of reaction mechanism, when given, are often of the flimsiest nature, leaning heavily on the ideas from quite different systems and ignoring relevant literature.

8 There have been no systematic studies of the importance of calcination conditions (temperature, time, gas composition, flow-rate, etc).

We stress that the reasons for these implied criticisms are understandable and forgivable, bearing in mind the multiplicity of variables and techniques available, and the tremendous scope of the field. What is advocated above is no doubt a counsel of perfection but there's nothing wrong with a little perfection!

\section{REACTION KINETICS}

The determination of orders of reaction and apparent activation energy ought to supply valuable information on reaction mechanism, as more than any other technique they speak directly of what is occurring at the active centres; and differences in their values ought to reveal changes in mechanism. Unfortunately, this is only true if measurements are made under the same or very similar conditions, but the data collected in Table 1 show that this is far from being the case. Thus, activation energies are measured either with a great excess of oxygen or with equimolar amounts: orders are measured at $217-353 \mathrm{~K}$ depending on the activity of the catalyst. Overarching generalizations will clearly be hard to find, but some attempt must be made.

Orders of reaction are invariably reported in a Power Rate Law form, ie as exponents of the reactant pressures. There has only been one attempt (6) to interpret results in terms of Langmuir-Hinshelwood kinetics (it was concluded that the reactants were adsorbed non-competitively), and only in three $(6,31$, $35)$ were orders measured at more than one temperature. There is one disturbing report (3) on reaction orders depending on the type of apparatus used. Orders in carbon monoxide are very variable; many are close to zero, indicating near saturation of the adsorption sites, but quite a few are in the range $0.25-$ 0.6 , suggesting weaker adsorption. Orders in oxygen are in general greater than for carbon monoxide $(-0.2-$ $0.4)$, but are sometimes low $(10,34)$ and on occasion lower than that for the reductant (10). Because of the variety of conditions and catalyst types, it is impossible to detect any clear connection between orders of reaction and catalyst structure.

In considering activation energies we may consult a helpful compilation (2) as well as Table 1: their values fall in three fairly distinct brackets. Several catalysts show values between 50 and $60 \mathrm{~kJ} \mathrm{~mol}^{-1}(2,35)$, and these include two of very low activity. Some, not all very active, show low values $\left(10-18 \mathrm{~kJ} \mathrm{~mol}^{-1}\right)$, while many including the most active have values between 24 and $41 \mathrm{~kJ} \mathrm{~mol}^{-1}$, averaging about $30 \mathrm{~kJ} \mathrm{~mol}^{-1}$. It would be nice if each range could be associated with a specific mechanism but there are indications (36) that activation energy varies with reactant pressures, and indeed with the temperature range used (10), so such an inference would be premature. Incidentally, attempts (2) to express activities in terms of turnover frequencies based on a presumed number of exposed gold atoms are likely to be misguided if the popular concept of reaction at the metal-support interface turns out to be correct.

\section{AN APPROACH TO UNDERSTANDING THE REACTION MECHANISM}

The practical application of any gold catalyst would demand (i) a totally reliable method for its manufacture, (ii) a knowledge of its long-term mechanical and catalytic stability, and (iii) information on its response to variations in operating conditions (temperature, $\mathrm{O}_{2} / \mathrm{CO}$ ratio etc). A fuller and better appreciation of the factors determining catalytic activity and the means of achieving it, and of the reaction kinetics and mechanism, are therefore essential for progress towards practical use.

What follows now is an attempt to rationalize and harmonize the body of information relating to goldcatalysed oxidation of carbon monoxide. It must be understood, however, that we are offering speculative but reasoned interpretations of the perplexing observations in the literature. One objective is to account for the divergent opinions as to whether the active species is $\mathrm{Au}^{0}$ or $\mathrm{Au}^{\mathrm{x}}$; a second is to understand the role played by the support, especially the claims (21) that disordered structures perform better; and a third is to consider whether the mechanism should be the same on all types of catalyst.

\section{The Interfacial Hypothesis}

Many authors have concluded on the basis of sound evidence that the site of very effective reaction is to be found at the junction between a small gold particle and 
a Transition Series metal oxide support $(2,3,10,19$, $29,37,38)$. This idea receives confirmation from the fact that (i) large (unsupported) gold particles are either inactive (39) or only poorly active (6) under comparable conditions; (ii) that large supported metal particles on alumina, silica and other oxides formed by impregnation with $\mathrm{HAuCl}_{4}$ solution and reduced in hydrogen are also of very low activity, (iii) that most support oxides by themselves have little if any activity, although $\mathrm{Fe}_{2} \mathrm{O}_{3}$ has been reported to have some (40); and (iv) that active catalysts can be made by depositing titania onto gold powder (39), or gold onto a titania single crystal (41). Clearly, where peripheral gold species are required, rate will increase as particle size is decreased, and it has been claimed that the expected quantitative relation can be observed (34). At the temperature needed to reduce the $\mathrm{AuCl}_{4}^{-}$ion, aggregation of the $\mathrm{Au}^{\circ}$ atoms will occur, and large particles will result. Furthermore, especially on alumina and titania, chloride ions will be hard to remove (except by washing or steam treatment), and they are likely to act in some way as a catalyst poison. Sodium ions on the other hand are said to promote the reaction and are usually present during depositionprecipitation (3),

\section{The Role of the Support}

A feature of the oxides of the elements from titanium to copper and zinc is their comparative ease of reduction by hydrogen or carbon monoxide. Numerous studies have described significant chemisorption of both oxygen and carbon monoxide on oxides used as supports (1): the general conclusion is that carbon monoxide on a support is unreactive or of low reactivity, while the behaviour of oxygen is more complex and perhaps more important $(8,37,38)$, depending much on the ease with which anion vacancies $\left(\square_{s}\right)$ can be created. With alumina and silica (42) it is most improbable that these can occur under normal conditions of pretreatment or reaction, so that oxygen chemisorption will be negligible and involvement of lattice oxide ions unlikely. In consequence the mechanism on large gold particles where there is no support participation and where the total length of the periphery is comparatively small will be of the Langmuir-Hinshelwood type, ie oxygen (weakly) and carbon monoxide (more strongly) adsorbed adjacently onto gold (42).

At least two of the preparative methods generate supports which initially are non-crystalline (they may in fact be hydroxides or hydrated oxides), and even after drying or calcination (if performed) may be highly disordered or of complex structure. This applies to Iwasawa's method and to coprecipitation: it is not clear to what extent deposition-precipitation may cause damage to the pre-exisiting support structure, although it is claimed that the presence of gold species (and even of triphenylphosphine) can cause erosion of the surface (2, 38). Good catalytic activity is, however, very often associated with disorder in the support, either generally or just in the neighbourhood of the gold particle. Such disorder may in part be caused by the heat released by chemisorption of the reactants (40).

There are several possible reasons for this. Use of freshly precipitated hydroxide undoubtedly encourages adsorption of the gold-phosphine precursor in a highly dispersed form, and therefore helps to achieve a small size of the ultimate gold particles. With coprecipitation, effective dispersion of the gold precursor $\left(\mathrm{Au}(\mathrm{OH})_{3}\right.$, $\mathrm{Au}_{2} \mathrm{O}_{3} \cdot \mathrm{xH}_{2} \mathrm{O}$ or $\mathrm{AuO}(\mathrm{OH})$ ) amongst the support particles is also guaranteed, although there is a risk of the active particles being buried within the support: therefore, we suggest that this is why calcination is needed - to create porosity by loss of water, and hence access to the gold particles. In disordered zones of the support it may also be easier to create anion vacancies into which oxygen molecules can be chemisorbed.

Structural complexity in the support is well exemplified by ferric oxide. Coprecipitation using sodium carbonate leads to the formation of 'ferrihydrite', a structurally disordered material having the composition $\mathrm{Fe}_{5} \mathrm{HO}_{8} .4 \mathrm{H}_{2} \mathrm{O}$ and to $\mathrm{FeO}(\mathrm{OH})$ (goethite), which after calcination transforms to $\alpha-\mathrm{Fe}_{2} \mathrm{O}_{3}$ (haematite) $(21,32)$. In Iwasawa's method, the initially formed $\mathrm{Fe}(\mathrm{OH})_{3}{ }^{*}$ upon calcination gives first a mixture of $\mathrm{Fe}_{3} \mathrm{O}_{4}$ (magnetite) and $\alpha-\mathrm{Fe}_{2} \mathrm{O}_{3}$ and at a higher temperature the $\mathrm{Fe}_{3} \mathrm{O}_{4}$ is oxidized to $\gamma-\mathrm{Fe}_{2} \mathrm{O}_{3}$ (2). Very active catalysts are obtained in both cases, but activity is not simply a function of BET area (2).

\section{The Oxidation State of the Gold}

A major bone of contention is the oxidation state of the gold in the active centre. As noted above, this is often inferred by methods such as XPS, XRD, and EXAFS, which employ conditions of vacuum and/or irradiation quite unlike those experienced during catalysis. Several different kinds of gold species have been identified using FTIR on chemisorbed carbon monoxide (42); these include $\mathrm{Au}^{\circ}$, in high or low coordination, "positively polarized" gold atoms at the periphery $(13,42)$, and gold species on which both carbon monoxide and oxygen atoms are adsorbed (1).

\footnotetext{
${ }^{*}$ Asterisk $\left({ }^{*}\right)$ denotes freshly precipitated
} 
Oxidation state is also inferred from the effect of pretreatment on activity: calcination (in air) is sometimes essential, sometimes beneficial, sometimes unnecessary and sometimes harmful. Oxidized gold species are unstable even in air, and decompose to $\mathrm{Au}^{0}$ as temperature is increased (22) : this change leads to loss of chemisorption capacity and catalytic activity. Change of activity during use has also been used to identify the oxidation state: deactivation is often observed and has been ascribed (20) to reduction of ions by carbon monoxide to $\mathrm{Au}^{0}$, as for example:

$$
\mathrm{Au}^{\mathrm{II}} \rightarrow \mathrm{Au}^{\mathrm{I}} \rightarrow \mathrm{Au}^{0}+\mathrm{Au}^{\mathrm{II}}
$$

although activities sometimes increase to begin with, before reaching a stable high level, eg when dried (ie noncalcined) materials are used (21). Most authors are quite strongly polarized in their views, believing that only $\mathrm{Au}^{0}$ $(3,10)$ or only $\mathrm{Au}^{\mathrm{x}+}(22,42)$ species are responsible for activity. The mode of action of the latter, and the reasons for their superiority over $\mathrm{Au}^{0}$, is not explained by those who believe in them, and no one seems to consider that the presence of both may be necessary. Electrocatalytic oxidation studies using gold electrodes $(1,43,44)$ strongly suggest that gold atoms having low coordination number $(\mathrm{CN})$ are more electropositive and are therefore more easily oxidized than those of high $\mathrm{CN}$, and this suggests that peripheral gold atoms in small supported particles may readily transform into ions. The simultaneous presence of both atoms and ions is therefore not ruled out.

\section{Chemisorption of Reactants and of Water}

It is, however, generally agreed that the carbon monoxide which is oxidizable is reversibly adsorbed on the gold (either $\mathrm{Au}^{0}$ or $\mathrm{Au}^{\mathrm{x}}$ ) $(19,37,38)$ ) if it is on the support it is as a strongly held spectator $(37,38)$ or as a stable carbonate ion $(3,10,38,41)$. The route for oxygen appears to involve its adsorption as a molecule or superoxide molecular ion $\left(\mathrm{O}_{2}{ }^{-}\right)$on anion vacancies in the surface of the supports, if these are easy to form $(37,38)$. Although several authors suggest that lattice oxide ions $\left(\mathrm{O}^{2-}\right)$ are the oxidant $(40)$, there is little direct evidence for this, and very clear indications that the active species is an oxygen molecule $(2,10,37,38)$ or $\mathrm{O}_{2}$. No dissociation of oxygen occurs except by reaction with carbon monoxide (37).

Various results have been reported for the effect of water on the reaction $(10,22,25,37,38)$. It sometimes increases the rate, perhaps by ensuring that some or all of the gold remains in an oxidized state (3), but it has no effect on $\mathrm{Au} / \mathrm{Fe}(\mathrm{OH})_{3}{ }^{*}$ (37) and acts as a poison on
$\mathrm{Au} / \mathrm{Ti}(\mathrm{OH})_{4}^{*}$ (38) and $\mathrm{Au} / \mathrm{TiO}_{2}$ (10), perhaps by occupying anion vacancies (ie hydrating the surface), and preventing oxygen adsorption. A positive role for surface hydroxyls has been suggested with magnesia (25), and indeed many of the oxide supports are likely to remain coated by at least a partial layer of hydroxyl ions during use. Water promotes the reaction on $\mathrm{Au} / \mathrm{MgO}$ at high temperature, but poisons it at low temperature (25). It has recently been noticed that with $\mathrm{Au} / \mathrm{Fe}_{2} \mathrm{O}_{3}$ the reaction does not proceed if the reactants are completely dry, but that $100 \%$ conversion occurs at $273 \mathrm{~K}$ when water is present even in traces**.

\section{Two Further Factors}

Before attempting harmonization of all these very diverse observations, two other factors need to be considered:

1 The reactivity of gold atoms may depend on their coordination number (CN), stronger chemisorption being shown theoretically for lower values of $\mathrm{CN}$ (45). The concept of varying electron density across steps on model surfaces is well established (46), and the fraction of edge atoms will obviously rise as particle size decreases $(1,45)$.

2 The stability of noble metal $\left(\mathrm{Pt}, \mathrm{Rh}_{\mathrm{h}}\right)$ particles on alumina and titania is attributed to a chemical glue' of metal cations at the interface between the support and the particle (see, for example, reference 47). At small particle sizes the fraction of the metal in ionic form can be quite high. Structures of this interfacial zone, and changes with ambient atmosphere, have been elucidated by EXAFS (47), but similar studies have not yet been performed with gold on reactive supports.

\section{Classes of Support}

It remains now to draw these threads together and in a very speculative way to imagine what structures may exist in gold catalysts that are active for carbon monoxide oxidation, and by what mechanisms the reaction may occur. It has been very sensibly suggested that it may be necessary to consider each type of catalyst by itself, and although for example $\mathrm{Au} / \mathrm{FeO}_{\mathrm{x}}$ catalysts made and pretreated in different ways may exhibit some different characteristics these must be considered in the framework of a single model. We will, therefore, adopt the following classification of supports:

$1 \mathrm{FeO}_{\mathrm{x}}$ (and perhaps other easily reducible oxides such as $\mathrm{Co}_{3} \mathrm{O}_{4}, \mathrm{NiO}, \mathrm{CuO}$, etc, for which detailed information is lacking)

\footnotetext{
${ }^{* *} \mathrm{G}$. J. Hutchings, personal communication
} 


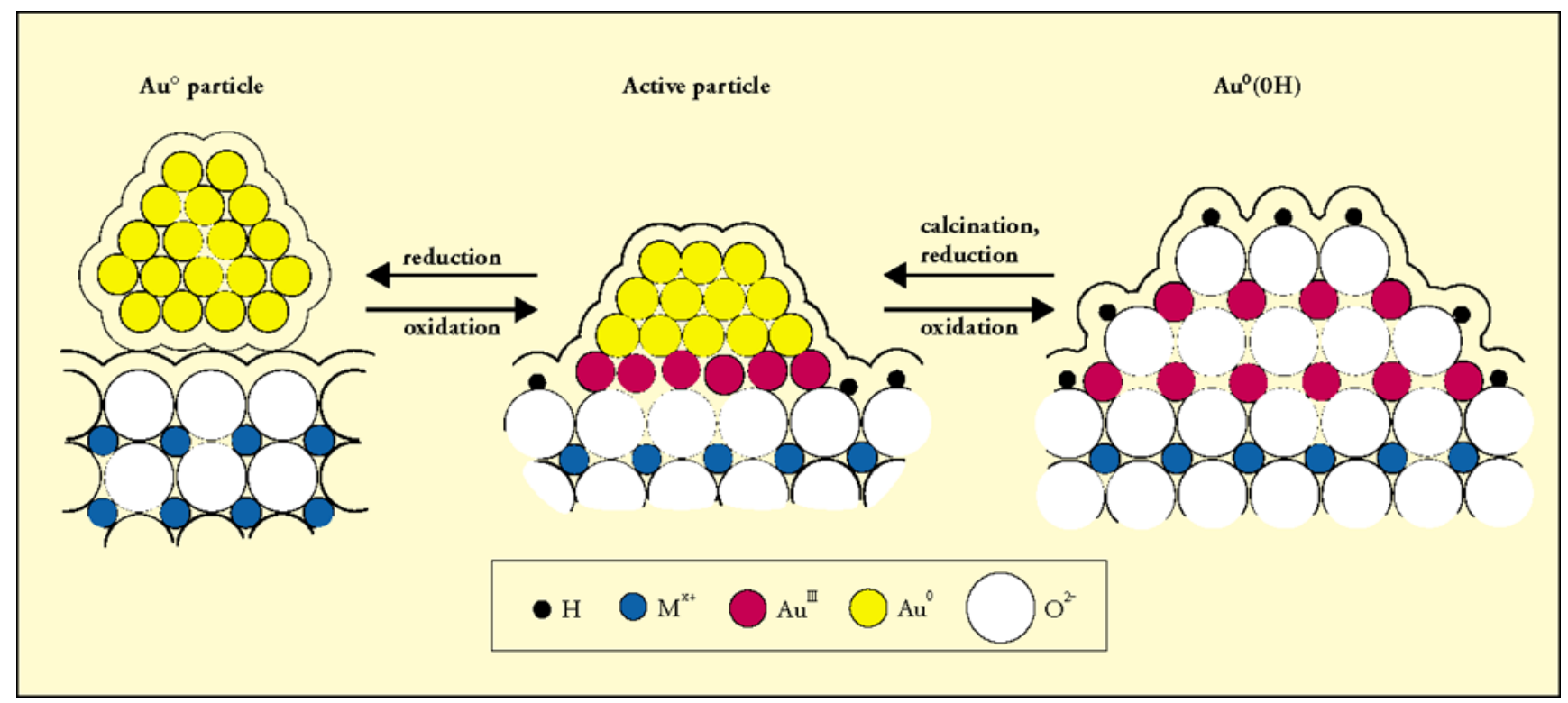

Figure 1 Pictorial representation of supported gold catalyst indicating possible changes under conditions giving oxidation or reduction of the active gold particles. The gold ions provide a 'chemical glue' which binds the particle to the support.

$2 \quad \mathrm{TiO}_{2}$ (and perhaps other less easily reducible oxides such as $\left.\mathrm{ZrO}_{2}\right)$

$3 \mathrm{MgO}$ (and perhaps other strongly basic supports)

$4 \mathrm{Al}_{2} \mathrm{O}_{3}, \mathrm{SiO}_{2}$.

We have already said something about alumina and silica as supports and there is only a little information available about magnesia $(23,25)$; we will, therefore, focus on the more commonly studied iron oxide and titania supports. Iwasawa's $\mathrm{Au} / \mathrm{FeO}_{\mathrm{x}}$ are more active than his $\mathrm{Au} / \mathrm{TiO}_{2}$ catalysts (2), probably because $\mathrm{FeO}_{\mathrm{x}}$ is the more easily reducible support and because the disordered structure noted above facilitates the formation of anion vacancies near gold particles: the reverse is, however, true for coprecipitation catalysts (3), which may suggest that anion vacancies are of lesser importance in this case.

\section{Possible Reaction Mechanisms}

We suggest that many of the reported observations can be understood on the basis of a model in which the active catalyst contains both gold atoms and ions (which we will take to be $A u^{\text {III }}$ ), and that the latter form the 'chemical glue' which binds the particle to the support (see Figure 1). Each particle is, therefore, bounded by a ring of $\mathrm{Au}^{\mathrm{III}}$ ions. The structure is not, however, fixed: the $\mathrm{AuI} I / \mathrm{Au}^{0}$ ratio may change (i) during calcination, when depending on temperature a certain fraction of the $A u$ III will autoreduce as oxygen is lost $(20,22)$, (ii) during reduction by hydrogen if performed (40), and (iii) during reaction, where initial changes in reactivity may reflect changes in this ratio $(10,20-22)$. Thus complete reduction, due to excessive calcination or use of hydrogen, is harmful because the glue is lost from the interface and sintering can then occur easily (Figure 1): but equally the total absence of $\mathrm{Au}^{0}$ is undesirable, as it is needed to provide a locus for the chemisorption of the carbon monoxide, and a partially reduced support surface may contain anion vacancies which assist oxygen adsorption.

Thus, the sense of initial activity changes will depend on the $\mathrm{Au}$ III $/ \mathrm{Au}^{0}$ ratio at the outset and on the $\mathrm{O}_{2} / \mathrm{CO}$ ratio used. We believe that not only reduction but also oxidation of the gold phase can occur during reaction, and we have noted the very widely varying reaction ratios that are used to measure activity (Table 1). This model can be refined to assign various tendencies for carbon monoxide to chemisorb on $\mathrm{Au}^{0}$ atoms of different $\mathrm{CN}$ (45). Large gold particles may possess only relatively small interfacial areas and few atoms having low $\mathrm{CN}$ and thus show only diminished activity.

It has been suggested in the case of magnesia (25) that the mechanism may start by a support hydroxyl ion attacking a carbon monoxide molecule on the gold (Au ${ }^{0} . . . \mathrm{CO}$ ). We think this may occur more generally, and propose a 'periphery' mechanism as follows. The $\mathrm{Au}^{0} \ldots \mathrm{CO}$ is attacked by an hydroxyl group either on a support cation or on a peripheral AuII ion, forming a carboxylate group attached to the latter. This is in turn attacked by a superoxide ion, which must be responsible for oxidizing two carboxylate ions: the hydroxyl group returns whence it came and is ready to re-engage in the 
catalytic cycle. Consequently, steps in the mechanism could include:

\begin{tabular}{|c|c|}
\hline $\mathrm{Au}^{0}+\mathrm{CO} \rightarrow \mathrm{Au}^{0} \ldots \mathrm{CO}$ & (1) \\
\hline $\mathrm{Au}^{\mathrm{II}}+\mathrm{OH}_{s}^{-} \rightarrow \mathrm{Au}^{\mathrm{II}} \ldots \mathrm{OH}$ & (2) \\
\hline $\begin{array}{l}\mathrm{Au}^{0} \ldots \mathrm{CO}+\mathrm{Au}^{\mathrm{II}} \ldots \mathrm{OH} \rightarrow \mathrm{Au}{ }^{\mathrm{II}} \ldots \mathrm{COOH}+\mathrm{Au}^{0} \\
\mathrm{O}_{2}+\square_{s}^{-} \rightarrow \mathrm{O}_{2}-\ldots \square_{s}\end{array}$ & $\begin{array}{l}\text { (3) } \\
\text { (4) }\end{array}$ \\
\hline \multirow{2}{*}{\multicolumn{2}{|c|}{$\begin{array}{l}\mathrm{Au}{ }^{I I} \ldots \mathrm{COOH}+\mathrm{O}_{2}^{-} \ldots \square_{\mathrm{s}} \rightarrow \mathrm{Au}^{\mathrm{II}}+\mathrm{CO}_{2}+\mathrm{HO}_{2}^{-} \ldots \square_{\mathrm{s}}(5) \\
\mathrm{Au}{ }^{\mathrm{II}} \ldots \mathrm{COOH}+\mathrm{HO}_{2}^{-} \ldots \square_{\mathrm{s}} \rightarrow \mathrm{Au}^{\mathrm{II}}+\mathrm{CO}_{2}+ \\
2 \mathrm{OH}_{s}^{-}+\square_{\mathrm{s}}(6)\end{array}$}} \\
\hline & \\
\hline $\mathrm{Au}^{\mathrm{II}}+\square_{s} \rightarrow \mathrm{Au}^{\mathrm{III}}+\square_{s}^{-}$ & (7) \\
\hline
\end{tabular}

The nett reaction, ie $2 \mathrm{CO}+\mathrm{O}_{2} \rightarrow 2 \mathrm{CO}_{2}$, is obtained by doubling the processes represented by Equations (1) - (3) and then adding all the processes in the set.

There is infrared evidence for the presence of both $\mathrm{Au}^{0} \ldots \mathrm{CO}$ and $\mathrm{Au}^{\mathrm{x}+} \ldots \mathrm{CO}$ species with the relevant absorptions occurring at 2112 and $2151 \mathrm{~cm}^{-1}$, respectively (42). It should be noted that $\mathrm{AmO}(\mathrm{OH})$ is detected by Mössbauer spectroscopy in pre-calcined ferrihydrite-supported catalyst (21) and $\mathrm{Au}^{+}$is present at the interface between gold and magnesium hydroxide support $(3,26)$. XPS results are also consistent with the presence of gold hydroxyl species on $\mathrm{Fe}_{2} \mathrm{O}_{3}, \mathrm{TiO}_{2}$, and $\mathrm{Al}_{2} \mathrm{O}_{3}(22)$.

A graphic representation of the initial stages of this mechanism is given in Figure 2. There the anion vacancy used in Equation (4) is created in Equation (2), and by implication is removed when the hydroxyl ion (which acts catalytically) is restored to the support surface in the process represented by Equation (6).

We noted above a suggestion that the mechanism might not be the same on all catalysts. Thus, for example, one possible variant of the above scheme might apply with those oxides or under those conditions where anion vacancies are not formed: the oxygen molecule might simply be weakly bonded to a support cation, instead of as in Equation (4). Similarly, where mobile support hydroxyls do not exist, reactions (2) and (3) will not take place, and the mechanism may entail direct reaction of a chemisorbed carbon monoxide with an oxygen molecule or a superoxide ion. Much of the detailed kinetic information currently available $(10,37$, 38 ) is confined to specific catalysts, and generalizations are hard to make.

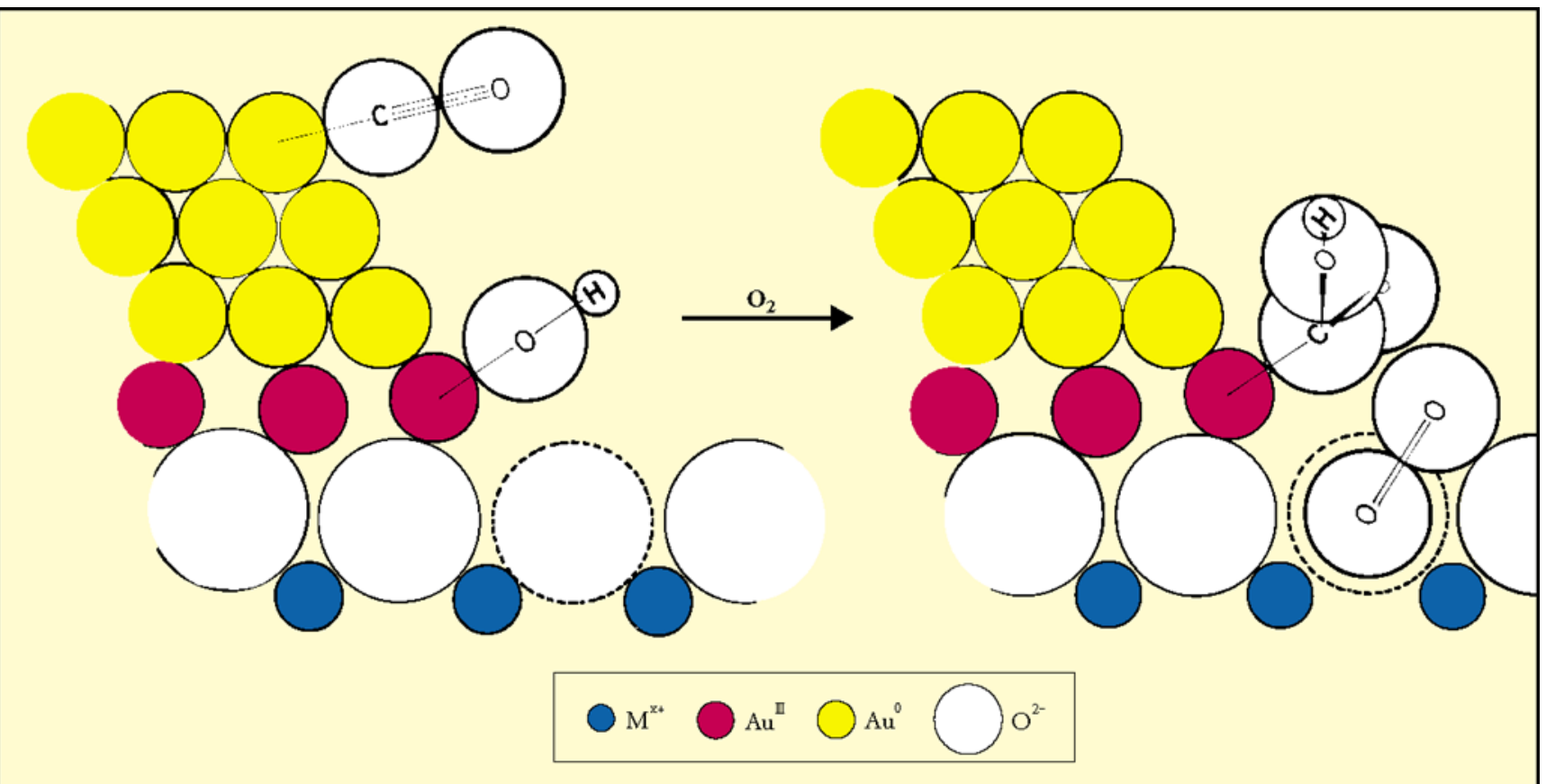

Figure 2 A representation of the early stages of the oxidation of carbon monoxide at the periphery of an active gold particle. At the lefi, a carbon monoxide molecule is chemisorbed on a low $C N$ gold atom, and an bydroxyl ion has moved from the support to an AuIII ion, creating an anion vacancy. At the right they have reacted to form a carboxylate group, and an oxygen molecule occupies the anion vacancy as $\mathrm{O}_{2}$. This then oxidizes the carboxylate group by abstracting a hydrogen atom, forming carbon dioxide, and the resulting bydroperoxide ion $\mathrm{HO}_{2}$ then oxidzes a further carboxylate species forming another carbon dioxide and restoring two bydroxyl ions to the support surface. This completes the catalytic cycle. No attempt is made to suggest the charges carried by the reacting species. 
However, in this manner we can understand (as in a glass darkly!) how contradictory conclusions about the occurrence and importance of $\mathrm{Au}^{\circ}$ and $\mathrm{Au}^{\mathrm{x}}$ species can arise both from physical methods of characterization (which can alter their ratio) and from chemical changes taking place during calcination and reaction. Subtler differences between the various types of oxide remain to be explored.

Whilst it is dangerous to generalize and draw conclusions on the basis of results recorded from a wide variety of catalysts operating under such diverse conditions, the mechanistic concepts advanced above provide a working hypothesis which may fit the current state of knowledge on gold catalysed carbon monoxide oxidation. If this is correct, then $\mathrm{Au}^{0}, \mathrm{Au}^{\mathrm{x}+}$, and the metal oxide support all have a role to play and the interaction of these species at the interface between the gold and the support is particularly important.

\section{Testing the Mechanism}

Any mechanistic concept has to withstand experimental test: of the several criteria to be applied to our proposal, perhaps the most significant would be detecting the simultaneous presence of $\mathrm{Au}^{\circ}$ and $\mathrm{Au}^{3+}$ (or perhaps $\mathrm{Au}^{+}$) in the working catalyst. Possibly EXAFS measurements might show if this is indeed the case, and find where the ions (if found) are located. The ratio of $\mathrm{Au}^{\mathrm{x}+}$ : $\mathrm{Au}^{0}$ should increase as the $\mathrm{O}_{2}$ : $\mathrm{CO}$ ratio is increased. Careful spectroscopic studies might indicate the presence of carboxylate or similar intermediate groups. Theoretical work using density functional theory should be directed towards disclosing the energy barriers involved in the $\mathrm{CO}$ $+\mathrm{OH}^{-}$reaction and to the oxidation of carboxylate ion by oxygen molecular ions $\left(\mathrm{O}_{2}{ }^{-}\right)$.

\section{POTENTIAL APPLICATIONS FOR CATALYSIS BY GOLD}

Practical applications for gold catalysts will naturally require reliable methods of manufacture and a secure knowledge of their long-term mechanical and catalytic stability as well as their performance criteria, including activity and durability under practical operating conditions. Nevertheless, there is no reason why such information should not become available in due course and the potential of these catalysts for pollution control, fuel cell, sensor, and chemical processing applications could then be realized.

It is possible that gold could be usefully incorporated into automobile catalysts: the price of palladium is currently rising rapidly due to the demands for low light off 'start-up' catalysts in these systems and supported gold has the potential of meeting at least some of the requirements for such systems. Some patents $(48,49)$ have been filed claiming gold catalysts for use in automobile pollution control (see Gold Bulletin, 1999, $32,30,102$ ). Their use in this application will, however, require demonstration of adequate stability at operating temperatures.

Preferential oxidation of carbon monoxide in hydrogen-rich reformer gas is effected by a gold catalyst $\left(\mathrm{Au} / \alpha-\mathrm{Fe}_{2} \mathrm{O}_{3}\right)$ which is significantly more active than the commercial PROX catalyst, ie $\mathrm{Pt} / \gamma$ $\mathrm{Al}_{2} \mathrm{O}_{3}$ (19). Gold catalysts are therefore likely to be considered for carbon monoxide removal from this type of gas stream, a process which is required for fuel cell applications. The hydrogen / oxygen reaction which is also used in fuel cells is catalysed by gold (1). Patents have been filed for the use of gold catalysts in fuel cells $(50,51)$. The removal of carbon monoxide from air to provide high purity nitrogen and oxygen has also been envisaged (52).

Haruta et al (3, 53, 54) have studied the absorbance of thin films of transition metal oxides (eg nickel, cobalt and copper oxides) containing gold and shown that by monitoring the absorbance change at two different wavelengths (eg 600 and $900 \mathrm{~nm}$ ) the recognition of hydrogen and carbon monoxide became possible when these gases are present at 1 vol $\%$ levels. Consequently, composite films of cobalt oxide crystals $(5-10 \mathrm{~nm})$ and small gold particles $(20-40 \mathrm{~nm}) \mathrm{can}$ form a basis for optical gas sensors to measure the levels of these two gases simultaneously.

\section{ACKNOWLEDGEMENTS}

We thank Donka Andreeva, Alfons Baiker, Masatake Haruta, Graham Hutchings, Yasuhiro Iwasawa, Ben Nieuwenhuis and Walter Vogel for providing reprints and preprints of their papers.

\section{ABOUT THE AUTHORS}

Geoffrey Bond held academic posts at Leeds and Hull Universities before joining Johnson Matthey plc in 1962 as Head of Catalysis Research. In 1970 he was appointed Professor in Brunel University's Chemistry Department, and is now an Emeritus Professor at that University.

David Thompson has a special interest in catalysis by gold, having previously held catalysis research posts in 
$\mathrm{ICI}$ and Johnson Matthey plc where he was involved in precious metals catalysis projects. In his current freelance work as a chemical consultant he advises on catalyst design for chemical processing, pollution control and gas detection. He is Technical Editor of Gold Bulletin.

\section{REFERENCES}

* The references denoted by an asterisk were also included in our previous review (1)

1 G.C. Bond and D.T. Thompson, Cat. Rew - Sci. Engy, 1999, 41, 319

2 A.I. Kozlow, A.P Kozlowa, H. Liu and Y. Iwasawa, Appl. Catal. A, Gem. 1999, 182,9

3 'The Abilities and Potential of Gold as a Catalyst', Report of the National Research Institute, Osaka, Japan, 1999

4 D.T.'Thompson, Gold Bull, 1998, 31, 111; 1999, 32, 12

5* N.W. Cant and WK. Hall, J. Phys. Chem, 1971, 75, 2914

$6^{*} \quad$ S.D. Lin, M. Bollinger and MA. Vannice, Catal. Leth, 1993, 17,245

$7^{*}$ WA. Bone and G.W. Andrew, Proc. Roy. Soc. (London), 1925, 109A, 459

8 Y. Tizuka, T. Tode, T. Takao, K. Yatsu, T. Takeuchi, S. Tsubota and M. Haruta, j. Catal, $1999,187,50$

9* M. Valden, X Lai and D.W. Goodman, Science, 1998, 281, 1647

$10^{*}$ M.A Bollinger and MA Vannice, Appl Cata B: Environmentai 1996, 8, 417

11 M. Valden, S. Pak, X Lai and D.W. Goodman, Catal Letters, 1998, 56,7

$12^{*}$ J.-D. Grunwaldt, C. Kiener, C. Wogerbauer and A. Baiker, J. Catai, 1999, 181, 223

13 J.-D. Grunwaldt, M. Maciejewski, O.S. Becker, P. Fabrizioli and A.Baiker, J. Catal, $1999, \mathbf{1 8 6 , 4 5 8}$

14 J.-D. Grunwaldt and A Baiker, J. Phys, Chem. B, 1999, 102, 1002

15 K. Sayo, S. Deki, and S. Hayashi, J. Colloid and Interface Saience, 1999, 212, 597

16 K. Sayo, S. Deki and S. Hayashi, J. Mater. Chem, 1999,9,937

17 VA. Bondzie, S.C. Parker and C.T. Campbell, Catal. Leth, 1999, 63, 143

18 M. Arai, M. Mitsui, J.-I. Ozaki and Y. Nishiyama, J. Colloid and hoterface Science, 1994 , 118,473

19 M.J. Kahlich, H.A Gasteiger and RJ. Behm, J. Catal, 1999, 182, 430

20 A.M. Visco, F Neri, G. Neri, A Donato, C. Milone and S. Galvagno, Phys. Chem. Chem. Phys, 1999, 1, 2869

21 RM. Finch, NA. Hodge, G.J. Hutchings, A. Meagher, QA. Pankhurst, M.RH. Siddiqui, FE. Wagner and R. Whyman, Phys. Chem. Chem. Phys, 1999, 1, 485

22 E.D. Park and I.S. Lec, J. Catai, 1999, 186, 1

23 A. Sanchez, S. Abbet, U. Heiz, W.D. Schneider, H. Haekkinen, RN. Barnett and U. Landman, J. Phy. Chem. A, 1999, 103(48), 9573

24 U. Heinz, A Sanchez, S. Abbet and W.-D. Schneider, Eur. Phys. J, D, 1999,9.35

25 D.A.H. Cunningham, W. Vogel and M. Haruta, Catal Leth, 1999, 63, 43

26 Y. Kobayashi, S. Nasu, M. Haruta and T. Tsubota, Kyoto Datigake Genshiro Jikkensho Gakujutsu Koenkai Hobunshe, 2000,34, 145

27 C. K. Chang, Y.J. Chen and C.T. Yeh, Appl Catal A, 1998, 174, 13

28 Y. Yuan, K. Asakura, AI. Kozlova, H. Wan, K Tsai and Y. Iwasawa, Catal Today, 1998, 44,333

29 N.J. Osipoff and N.W. Cant, Topics in Catahysis, 1999, 8, 161

30 K.-H Choi, B.-Y. Koi and H.-I. Lee, Catal Today, 1998, 44, 205

31 B.E Niewenhuys, M.A.P. Dekkers and Y.]. Mergler, Polish Journal of Environmental Studies, $1997,6,53$

$32^{*}$ FE. Wagner, S. Galvagno, C. Milone, A.M. Visco, L. Stevano and S.D. Calogero,
J. Chem. Soc. Foraddy Trdors, $1997,93,3403$

33 D.A.H. Cunningham, W. Vogel, RM. Torres Sanchez, K. Tanaka and M. Haruta, f. Catth, 1999, 183, 24

$34^{*}$ M. Haruta, S. Tsubota, T. Kobayashi, H. Kageyama, M.J. Genet and B. Delmon, ]. Catdis, 1993, 144, 175

35* W. Lin and M. Flytzani-Stephanopoulos, $/$. Catal, 1995, 153, 304, 317.

36 F. Bocuzzi, A Chiorino, M. Manzoli, D. Andrecra and T. Tabakora, J. Catal, 1999, 188,176

37 (a) H. Liu, A.I. Kozlov, A.P. Kozlova, T. Shido and Y. Iwasawa, Phys. Chem. Chem Pbys, 1999, 1, 2851; (b)* A.P Kozlova, A.I. Kozlor, S. Sugiyama, Y. Matsui, K. Asakura and Y. Iwasawa, J. Catdl, 1999, 181,37

38 H. Tiu, A.I. Kozlor, A.P. Kozlova, T. Shido, K. Asakura and Y. Iwasawa, J. Cathd, 1999, 185,252

39* Z.M. Liu and M.A. Vannice, Catal. Let , 1997, 43,51

40 (a) A.K. Tripathi, VS. Kamble and N.M. Gupta, J. Catal, 1999, 187, 332; (b) N.M. Gupta and A.K. Tripathi, ]. Catal, 1999, 187,343

41 (a) VA. Bondzie, S.C. Parker and C.T. Campbell, J. Sci. Vac. Technol A, 1999, 17, 1717; (b) S.C. Parker, A.W. Grant, V.A Bondzie and C.T. Campbell, Surf. Sci, 1999 , 441,10

42 (a) M.A.P. Dekkers, M.J. Lippits and B.E. Nieuwenhuys, Catd Leth, 1998, 56, 195 (b) MA.P. Dekkers, M.J. Lippits and B.E. Nieuwenhuys, Catal Toddy, 1999, 54, 381

$43^{*}$ L.D. Burke and P.F Nugent, Gold Bull, 1998, 31, 39

44 L.D. Burke and P.F Nugent, Gold Bull, 1997, 30, 143

45 M. Marrikakis, P. Stolze and J.K. Norskov, Catal Leth, 2000, 64, 101

46 L.M. Falikov and G.A Somorjai, Proc. Am. Sci. USA, 1985, 82, 2207

47 FWH. Kampers and D.C. Konigsberger, Faraday Dis. Chem. Soc, 1990, 89, 137

48 LA. Petrov, Laman Consultancy Ltd, Bulgaria, W. Patent 9851401 A1 19981119

49 P. Marecot and R Emmanuel, Rhone Poulenc Chimie, French Patent 2771310 A1 990528

50 Gold Catalyst for Fuel Célls, V.M. Tatcher, Laman Consultancy, Bulgaria, WO. Patent $9916546 \mathrm{Al} 990408$

51 B. Grigorova, J. Mellor and J.AJ. Tumilty, Anglo American Research Laboratories, South Africa, WO Patent 2000013791 Al (16 Mar 2000)

$52^{*}$ M. Haruta, Catd Toddy, 1997, 36, 153

$53^{*}$ M. Ando, T. Kobayashi and M. Haruta, Catal. Toda, 1997, 36, 135

54* MAndo, T. Kobayashi, S. Tijima and M. Haruta, J. Mater. Chem, 1997, 7, 1779

55 L. Prati and G. Martra, Gold Bull., 1999, 32,96

56 TA. Nijhuis, B.J. Huizinga, M. Makkee and J.A Moulijn, Ind. Eng. Chem. Res, 1999, 38,884

57 YA. Kalvachey, T. Hayashi, S. Tsubota and M. Haruta, J. Catal, 1999, 186, 228

58 B.S.Uphade and M. Haruta, Appl Catal, $A$ (Generd), 1999, 190, 43

59 O. Kajikawa, X-S. Wang, T. Tabata and O. Okada, Orgunohalogen Compoumds, 1999, 40.581

60 H. Li, Y.-Y. Luk and M. Mrkisch, Langmuir, 1999, 15 (15), 4957

61 D. Andreera and T. Tabakova, Proc Europa Cat-4, Rimini, Italys September, 1999, p. 699

62 J.E Bailie and G.J. Hutchings, Chem, Commun, 1999, 2151

63 H.-G.Ahn and H. Nilyama, Kongop Hwahak, 1999, 10 (7), 1003

64 E. Seker, J. Cavataio, E. Gulari, D. Lorpongpaiboon and S. Osuwan, Appl Catal A, 1999, 183, 121

65 W. Cwikla and D. Naimek, Adsorpt. Sci Techroh, 1998, 16,773

66 A Ueda and M. Haruta, Gold Bull, 1999,32,3

67 T.Wang and J.A. Broussard, Celanese Intemational Corporation, WO Patent 9962632 